\title{
Surface Interaction between Ethylene, Hydroxide Ion, and Titanium Dioxide Anatase (001): A First Principle Density Functional Theory Study
}

\author{
Paulus Himawan ${ }^{1}$, Mohammad Kemal Agusta ${ }^{1}$, Hermawan Kresno Dipojono $^{1 *}$, Ganes Shukri ${ }^{2}$, Nugraha ${ }^{1}$ \\ ${ }^{I}$ Faculty of Industrial Technology, Bandung Institute of Technology, Jalan Ganesha 10, Bandung 40132, Indonesia. \\ ${ }^{2}$ Departement of Applied Physics, Graduate School of Engineering, Osaka University, 2-1 Yamada-oka, Suita, Osaka 565-0871, Japan.
}

Received: 18 September 2014 / Accepted: 30 November 2014

\begin{abstract}
:
This study covers surface interaction between ethylene, hydroxide ion, and $\mathrm{Ti}_{5 \mathrm{C}}$ adsorption site of titanium dioxide anatase (001). The result of the relaxation suggests that stability was reached on $\mathrm{Ti}_{5 \mathrm{C}}$ site with the adsorption energy of $-0.57 \mathrm{eV}$, while the changes in the bond length and angle between atoms on ethylene were negligible. Calculation of states density suggests that there was no orbital splitting between HOMO and LUMO states of ethylene after bonding, indicating that there was no covalent chemical bond formed, and hence the bond can be categorized as physisorption. It can be concluded that ethylene was adsorbed weakly on (001) surface of titanium dioxide, which was also line with the previous result. Meanwhile, the potential energy surface calculation between ethylene and hydroxide ion revealed that hydroxide ion was more stable in $\mathrm{Ti}$ site of $\mathrm{TiO}_{2}$. The bond energy calculation of co-adsorption between ethylene and hydroxide ion suggests that adsorption tends to be happened chemically with the bond energy of $-2.56 \mathrm{eV}$, which means that hydroxide ion may give significant effect to the adsorption of ethylene.
\end{abstract}

Key words: Adsorption, bonding energy, ethylene, density of states, Density Functional Theory, hydroxide ion, titanium dioxide anatase (001)

\section{Introduction}

The role of Titanium Dioxide as a catalyst has been discussed broadly. This catalyst has mainly chosen due to its low cost, environmental friendly and also chemically stable catalyst compared to other candidates such as $\mathrm{KmnO}_{4}, \mathrm{O}_{3}$, carbon, zeolite, and palladium [1-6]. Titanium dioxide has many applications for industrial processes such as being a catalyst for water splitting reaction [7], a reaction which converts water into hydrogen and oxygen. This catalyst also being an important catalyst for ethylene degradation reaction, which is being produced in ripe ning process of fruits and vegetables.

Naturally, fruits produce ethylene gas during ripening process. The accumulation of ethylene gas around the fruits will stimulate ripening reaction $[8,9]$. Hence, ethylene that is being produced must immediately be abated or converted to other compounds so that it can't stimulate ripening process of those fruits. Experimental works have shown that $\mathrm{TiO}_{2}$ could be a good catalyst to convert ethylene into other compounds $[10,11]$.

The previous works suggested the reaction pathway of the degradation reaction of ethylene [11-13]. Hauchechorne [12] gained the degradation reaction pathway by comparing the IR-spectral data from FTIR measurements. The bond between $\mathrm{C}=\mathrm{C}$ of ethylene is suggested to be broken, forming carbon dioxide $\left(\mathrm{CO}_{2}\right)$ by adding OH-radicals. The proposed total reaction pathway is as follows:

$$
\mathrm{C}_{2} \mathrm{H}_{4}+12 \mathrm{OH} \cdot \rightarrow 2 \mathrm{CO}_{2}+8 \mathrm{H}_{2} \mathrm{O}
$$

using $\mathrm{Ti}_{5} \mathrm{O}_{4} \mathrm{H}_{4}$ crystal as catalyst. The $\mathrm{Ti}_{5} \mathrm{O}_{4} \mathrm{H}_{4}$ crystal is formed from $\mathrm{TiO}_{2}$ by water splitting reaction as follows:

$$
\begin{gathered}
\mathrm{TiO}_{2}+\mathrm{hv} \rightarrow \mathrm{e}^{-}+\mathrm{h}^{+} \\
\mathrm{H}_{2} \mathrm{O}+\mathrm{h}^{+} \rightarrow \mathrm{OH} \bullet+\mathrm{H}^{+} .
\end{gathered}
$$

The $\mathrm{H}^{+}$ion will then combined with $\mathrm{TiO}_{2}$ to form the $\mathrm{Ti}_{5} \mathrm{O}_{4} \mathrm{H}_{4}$ crystal.

This study will focus on ethylene interaction to the (001) surface of $\mathrm{TiO}_{2}$ anatase form crystal, using $\mathrm{OH} \cdot$ as radical ions and $\mathrm{TiO}_{2}$ as catalyst. The anatase (001) surface of $\mathrm{TiO}_{2}$ is chosen due to its higher reactivity for catalytic activities [14-24] compared to the more stable (101) surface $[25,26]$.

\section{Experimental}

In this work, Density Functional Theory calculations are performed using Quantum Espresso [27] (Open Source Package for Research in Electronic Structure, Simulation, and Optimization), an UNIX-based open source software which uses plane-wave basis set. GGA (Generalized Gradient Approximation) exchange correlation with PBE (Perdew-Burke-Ernzerhof) [28,29] pseudopotential are used. The kinetic cutoff energy of $520 \mathrm{eV}$ are used in all calculations. The optimized bulk parameter of Titanium Dioxide are obtained from the previous result [30] which is $\mathrm{a}=\mathrm{b}=3.826 \AA$ and $\mathrm{c}=9.661 \AA$.

\footnotetext{
*Corresponding author: Hermawan Kresno Dipojono,

E-mail: dipojono@tf.itb.ac.id
} 
The anatase (001) surface of Titanium Dioxide is obtained by cutting the bulk crystal along its (001) plane. All slabs are separated with $21 \AA$ vacuum to make sure that there are no interaction between the surface and its periodically repeated cell. The surface is periodically repeated in a supercell of $(2 \times 2)$ unit cell. The calculation is performed under the concentration of $0.25 \mathrm{ML}$ (monolayer), which means one ethylene molecule is adsorbed in every four unit cells, with the additional of $\mathrm{OH} \cdot$ in every ethylene molecule. Integration in Brillouin zone with the k-points of $4 \times 4 \times 1$ is used to sample the reciprocal space.

During all geometry optimizations, two lower slabs are frozen while two upper slabs are allowed to relax. The adsorption energy is counted using this formula:

$\mathrm{E}_{\text {ads }}=\mathrm{E}_{\text {(adsorbate/surface) }}-\left(\mathrm{E}_{\text {adsorbate }}+\mathrm{E}_{\text {surface }}\right)$

where $E_{a d s}$ is the adsorption energy of the molecule, $E_{\text {surface }}$ is the energy of clean anatase (001) surface of $\mathrm{TiO}_{2}, \mathrm{E}_{\text {adsorbate }}$ is the energy of ethylene molecule and $\mathrm{OH} \cdot$ ion, while $\mathrm{E}_{\text {(adsorbate/surface) }}$ is the total energy of adsorbed molecule together with $\mathrm{TiO}_{2}$ surface.

Meanwhile, the charge transfer calculations were done using this formula:

$$
\mathrm{q}_{\text {net }}=\mathrm{q}_{\text {(adsorbate/surface })}-\left(\mathrm{q}_{\text {adsorbate }}+\mathrm{q}_{\text {surface }}\right)
$$

Where $\mathrm{q}_{\text {net }}$ is the net charge, $\mathrm{q}_{\text {surface }}$ is the charge of clean anatase (001) surface of $\mathrm{TiO}_{2}, \mathrm{q}_{\text {adsorbate }}$ is the charge of ethylene molecule and $\mathrm{OH} \bullet$ ion, while $\mathrm{q}_{\text {(adsorbate/surface) }}$ is the total charge of adsorbed molecule together with $\mathrm{TiO}_{2}$ surface. The isovalue rendering [31] is set to be \pm 0.002 (Bohr $^{3} /$ electrons $)^{0.5}$ for all charge transfer plots.

\section{Results and Discussion}

\section{Geometry optimizations}

All ethylene adsorptions are performed on the top site of $\mathrm{Ti}_{5 \mathrm{C}}$ adsorption site or 5-fold-coordinated titanium, which corresponds to $\pi$-bonded ethylene. Figure 1 . shows the ethylene molecule placed on the top of $\mathrm{Ti}_{5 \mathrm{C}}$ site, with the $\mathrm{C}=\mathrm{C}$ bond of ethylene parallel with $[1,0,0]$ direction. This site is chosen due to the fact from the previous works that ethylene is most likely to be adsorbed in $\mathrm{Ti}_{5 \mathrm{C}}$ site.

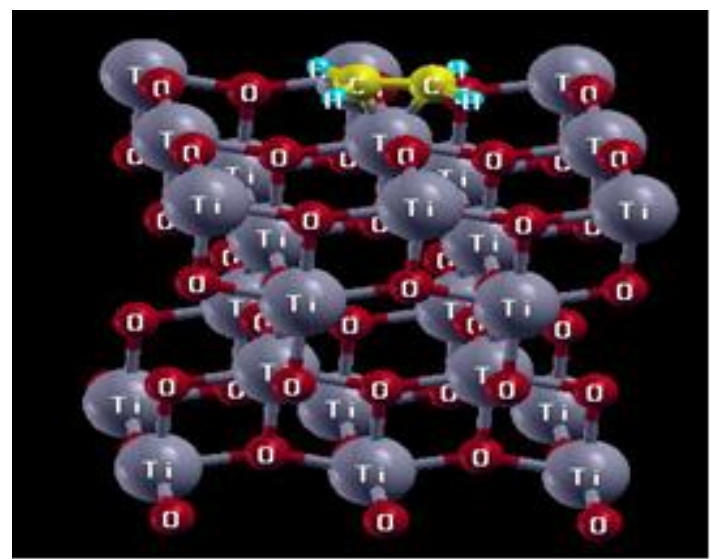

Figure 1. Adsorbed ethylene on $\mathrm{Ti}_{5 \mathrm{C}}$ site.
After the adsorption of ethylene is performed, it is found that ethylene is adsorbed weakly with the adsorption energy of $-0.57 \mathrm{eV}$. Also, there are slight changes in the bond lengths of ethylene molecule compared to isolated gas phase of ethylene molecule. The $\mathrm{C}=\mathrm{C}$ bond was calculated to be $1.32 \AA, 0.01 \AA$ shorter than $\mathrm{C}=\mathrm{C}$ bond of isolated ethylene which is $1.33 \AA$. This result is consistent with the previous result [30]. Meanwhile, the distance from the $\mathrm{C}$ atom of ethylene to its nearest $\mathrm{Ti}_{5 \mathrm{C}}$ is calculated to be $2.90 \AA$.

Furthermore, the $\mathrm{OH} \cdot$ ion is introduced to the $\mathrm{TiO}_{2}$ surface. The PES (potential energy surfaces) calculation is first performed before relaxing the structure to find the site in $\mathrm{TiO}_{2}$ surface that is most likely to adsorb the $\mathrm{OH}$ • ion. The result is then plotted in a $3 \mathrm{D}$ diagram which can be seen in Figure 2. The calculation result suggests that $\mathrm{OH} \bullet$ is more likely to be adsorbed on $\mathrm{Ti}$ sites of $\mathrm{TiO}_{2}$ due to its smaller relative adsorption energy compared to those on $\mathrm{O}$ sites.

The co-adsorption calculation is then performed using the ethylene adsorbed on $\mathrm{Ti}_{5 \mathrm{C}}$ site and $\mathrm{OH} \bullet$ on one of $\mathrm{Ti}$ site of $\mathrm{TiO}_{2}$. Figure 3. shows the visualized structure of the co-adsorption of ethylene molecule and $\mathrm{OH} \bullet$ ion on $\mathrm{TiO}_{2}$ surface.

(2)

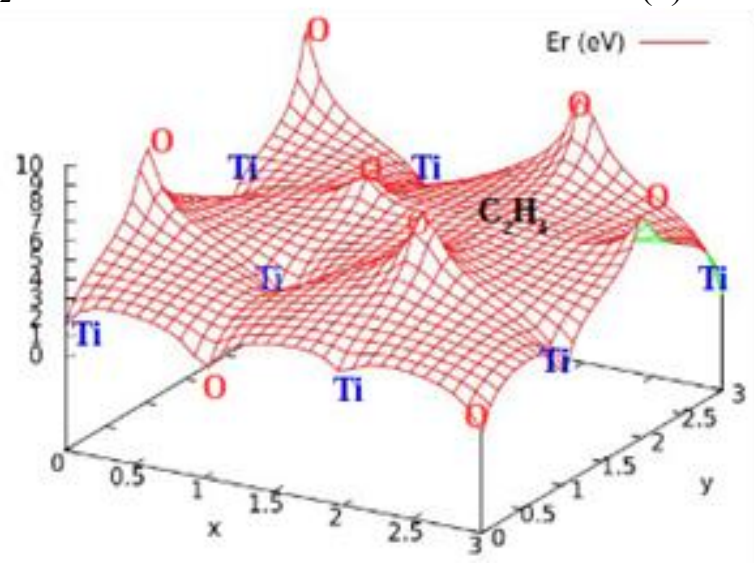

Figure 2. PES calculation of $\mathrm{OH} \bullet$ ion.

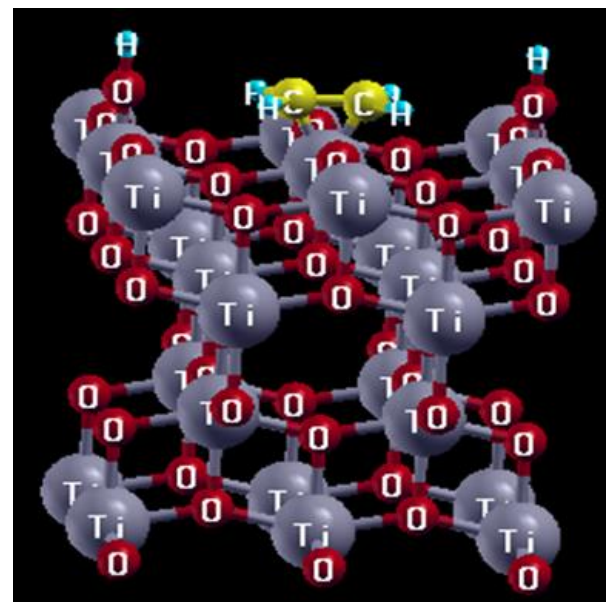

Figure 3. Co-Adsorption of ethylene molecule and $\mathrm{OH} \bullet$ ion on $\mathrm{TiO}_{2}$ surface. 

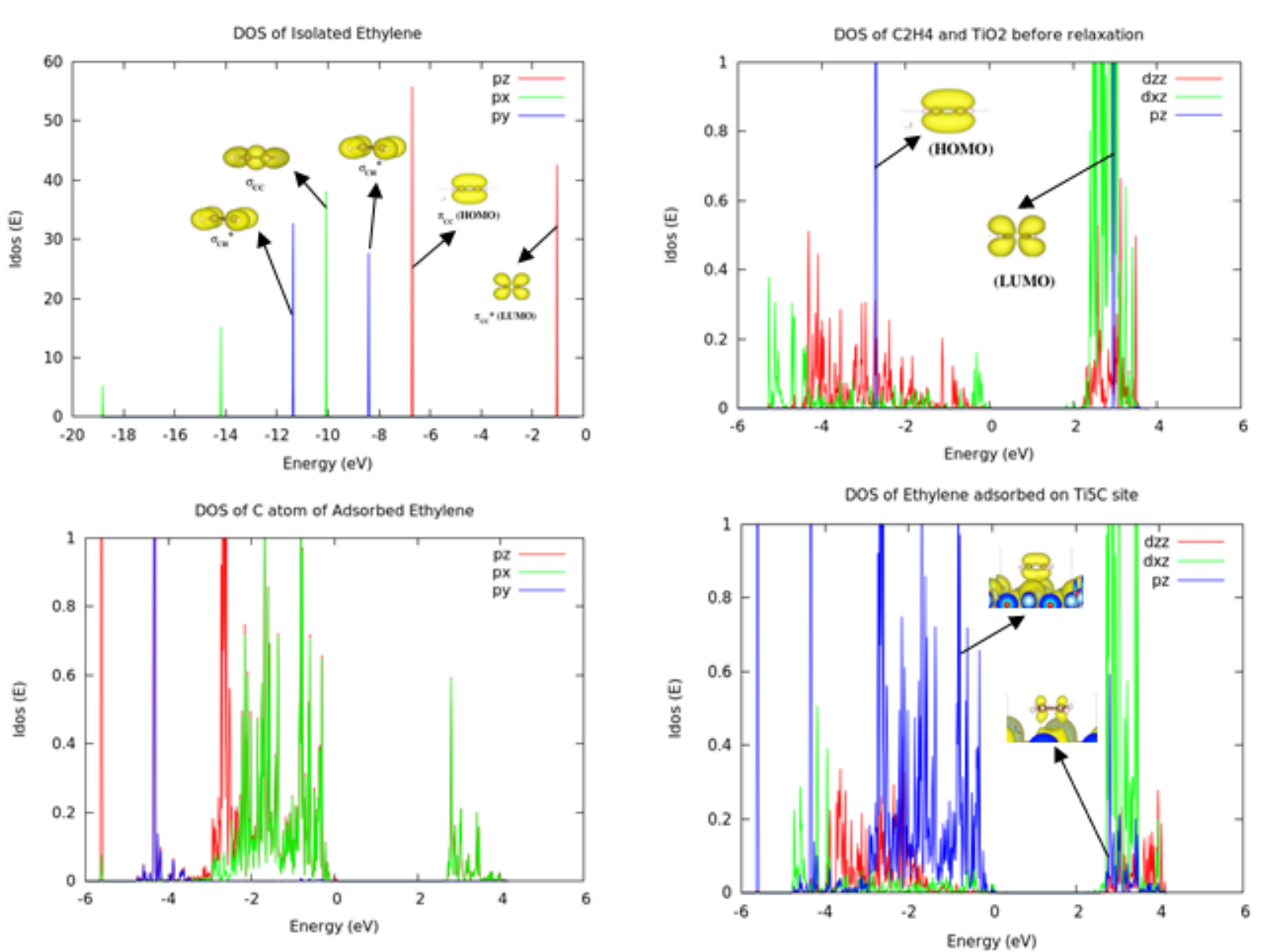

Figure 4. DOS (Density of States) of the interaction between ethylene molecule and $\mathrm{Ti}_{5 \mathrm{C}}$ site of $\mathrm{TiO}_{2}$. From upper left to lower right are a) DOS of isolated ethylene molecule, b) DOS of $p_{z}$ orbital of ethylene molecule projected on $d_{z z}$ and $d_{x z}$ orbital of Ti $i_{5 C}$ site before relaxation, c) DOS of $\mathrm{C}=\mathrm{C}$ atoms of ethylene after relaxation, and d) DOS of adsorbed ethylene on $\mathrm{Ti}_{5 \mathrm{C}}$ site. The Fermi Energy is set to $0 \mathrm{eV}$.

The co-adsorption energy is calculated to be $-2.56 \mathrm{eV}$, which is larger compared to the adsorption energy of ethylene molecule alone. Thus it should be analyzed further whether this adsorption energy comes mainly from the ethylene to its $\mathrm{Ti}_{5 \mathrm{C}}$ site or $\mathrm{OH} \bullet$ ion to its most stable Ti site. The $\mathrm{C}=\mathrm{C}$ bond length of ethylene is calculated to be $1.34 \AA$, slightly longer than that of isolated ethylene, while the molecule itself remains stable during and after relaxation. Meanwhile, the distance from the $\mathrm{C}$ atom of ethylene and $\mathrm{Ti}$ atom of $\mathrm{TiO}_{2}$ goes farther, which is calculated to be $3.15 \AA$. It can be suggested from these signs that the bond between $\mathrm{C}=\mathrm{C}$ atom of ethylene is getting weaker after the presence of $\mathrm{OH} \bullet$ ion.

\section{Electronic structures}

All calculations of electronic structures of ethylene are done by computing the LDOS (Local Density of States) of isolated ethylene molecule and adsorbed ethylene molecule with and without the presence of $\mathrm{OH} \bullet$ ion. Figure 4a) shows the local density of states of the orbitals of ethylene. The HOMO (Highest Occupied Molecular Orbital), known to be $\pi_{\mathrm{CC}}$, and LUMO

(Lowest Unoccupied Molecular Orbital) of ethylene,known to be $\pi^{*}{ }_{C C}$ are composed by its $C=C p_{z}$ (bonding) and $\mathrm{p}_{\mathrm{z}}{ }^{*}$ (antibonding) orbital, while $\mathrm{p}_{\mathrm{x}}$ and $\mathrm{p}_{\mathrm{y}}$ orbitals of ethylene are its $\mathrm{C}-\mathrm{C}$ bond $\left(\sigma_{\mathrm{CC}}\right)$ and $\mathrm{C}-\mathrm{H}$ bond $\left(\sigma_{\mathrm{CH}}\right)$, respectively. The gap between the bonding and antibonding orbital of ethylene is calculated to be around $5.5 \mathrm{eV}$, which finds good agreement with the previous result [30,32].

The calculation of local density of states ethylene adsorbed on $\mathrm{Ti}_{5 \mathrm{C}}$ site of $\mathrm{TiO}_{2}$ before and after relaxation is plotted in Figure 4b) and Figure 4d) respectively. The $\mathrm{d}_{\mathrm{zz}}$ and $\mathrm{d}_{\mathrm{xz}}$ orbital of $\mathrm{Ti}_{5 \mathrm{C}}$ are chosen due to their symmetry with the HOMO and LUMO of ethylene. It is observed that the $\pi_{\mathrm{CC}}$ and $\pi^{*}{ }_{\mathrm{CC}}$ of ethylene is broadened due to its interaction with the $\mathrm{d}_{\mathrm{zz}}$ and $\mathrm{d}_{\mathrm{xz}}$ orbital of $\mathrm{Ti}_{5 \mathrm{C}}$. However, there are no significant overlapping between HOMO and LUMO orbitals of ethylene after relaxation, suggesting that there are no significant filling of electron to the LUMO of ethylene. There are also no new orbitals formed, suggesting that the $\mathrm{C}=\mathrm{C}$ bond of ethylene is not broken. Thus it can be concluded that the interaction between ethylene and $\mathrm{TiO}_{2}$ at $\mathrm{Ti}_{5 \mathrm{C}}$ site could be categorized as physisorption or weak interaction. 

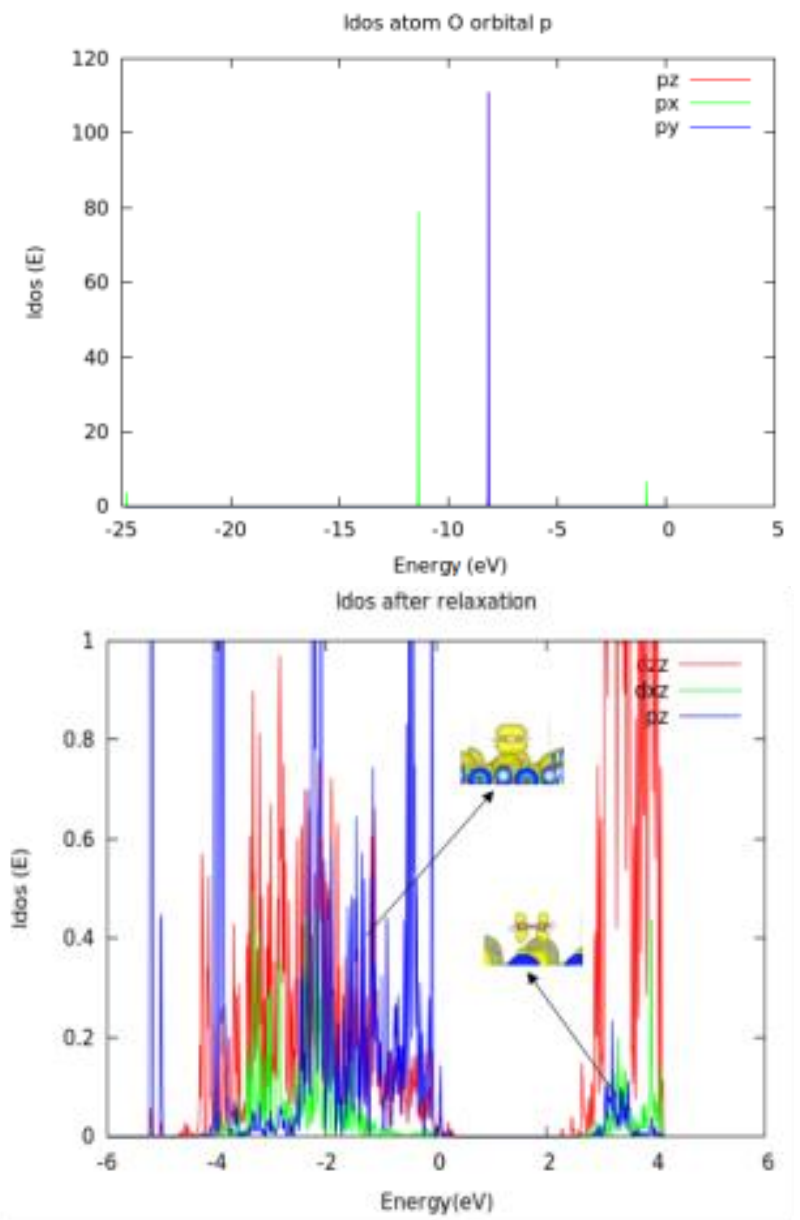

Figure 5. DOS (Density of States) of the interaction between ethylene molecule, $\mathrm{OH} \bullet$ ion, and $\mathrm{Ti}_{5 \mathrm{C}}$ site of $\mathrm{TiO}_{2}$. The upper picture is a) DOS of isolated $\mathrm{OH} \bullet$ ion while the lower picture is b) DOS of co-adsorption of ethylene molecule and $\mathrm{OH} \bullet$ ion to the $\mathrm{Ti}_{5 \mathrm{C}}$ site.

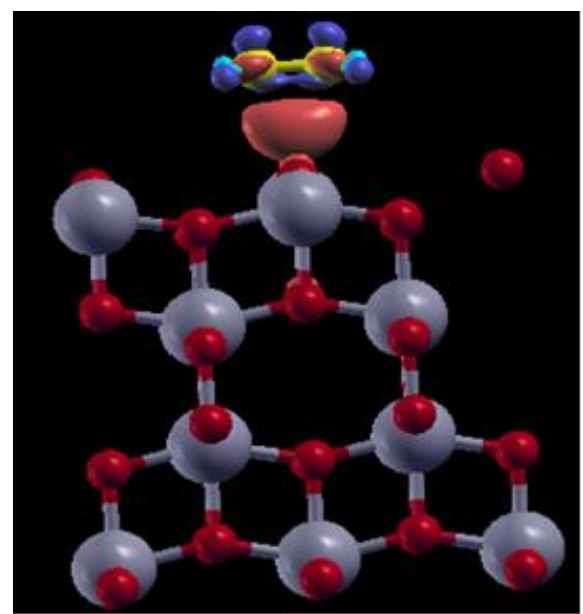

Figure 6. Charge transfer before and after ethylene adsorption (without the presence of $\mathrm{OH} \bullet$ ion). Decreasing charge is shown in blue while increasing charge is shown in red.

Moreover, the effect of the $\mathrm{OH} \bullet$ co-adsorption is found to make a significant contribution to the local density of states of ethylene, which can be seen in Figure 5b). The electron density of bonding orbital of ethylene is found to be increased after the presence of $\mathrm{OH} \bullet$ ion. This sign can lead us to two possibilities.

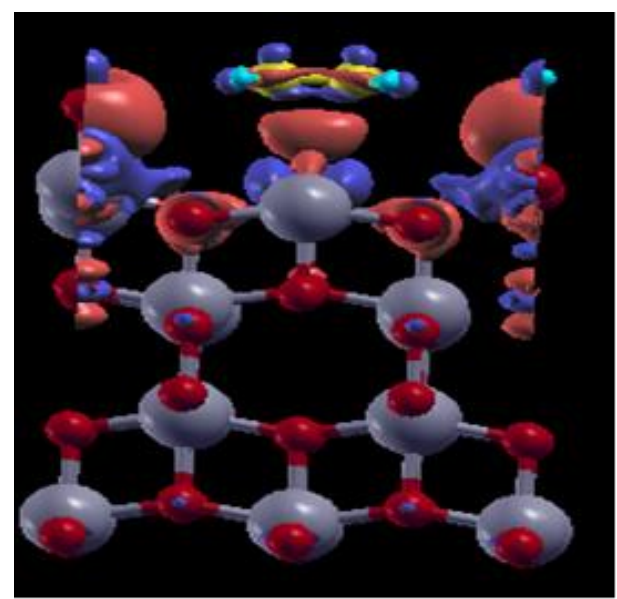

Figure 7. Charge transfer before and after co-adsorption (with the presence of $\mathrm{OH} \bullet$ ion). Decreasing charge is shown in blue while increasing charge is shown in red.

The adsorption of ethylene to $\mathrm{Ti}_{5 \mathrm{C}}$ site is getting stronger, or its increasing density could be the sign of $\mathrm{OH} \bullet$ ion which is adsorbed to $\mathrm{Ti}_{5 \mathrm{C}}$ site. Based on geometrical optimization calculation it can be concluded that the increasing density is caused mainly by the interaction of $\mathrm{OH} \bullet$ ion with $\mathrm{Ti}_{5 \mathrm{C}}$ site. However, there are no new orbitals formed so that the $\mathrm{C}=\mathrm{C}$ bond of ethylene may not be broken.

\section{Charge transfer plots}

The calculation of charge transfer is done to investigate the movement of electron charges before and after ethylene adsorption with and without the presence of $\mathrm{OH} \bullet$ ion. It can be seen in Figure 6. that there is accumulation of charge at the top of $\mathrm{Ti}_{5 \mathrm{C}}$ site of $\mathrm{TiO}_{2}$ while the electron charges of ethylene molecule is found to be decreased after relaxation. Hence, it can be concluded that ethylene was covalently bonded to the $\mathrm{Ti}_{5 \mathrm{C}}$ site.

It is also found that the activity of charge transfers of the surface is increasing after the presence of $\mathrm{OH} \bullet$ ion. As can be seen in Figure 7. that $\mathrm{OH} \bullet$ ion is strongly bonded to its most stable $\mathrm{Ti}$ adsorption site. However the ethylene molecule was still covalently bonded to the $\mathrm{Ti}_{5 \mathrm{C}}$ site.It is later observed that $\mathrm{OH} \bullet$ ion interacts strongly with its most stable $\mathrm{Ti}$ site and also with $\mathrm{Ti}_{5 \mathrm{C}}$ site, and at the same time the $\mathrm{OH} \bullet$ ion makes the bond between $\mathrm{C}=\mathrm{C}$ atoms of ethylene getting weaker.

\section{Conclusions}

The interaction between titanium dioxide anatase $(0,0,1)$ surface, ethylene molecule, and hydroxide ion has been investigated by using density functional theory study. The geometry optimization calculation suggests that the bonds between ethylene is not significantly changed before and after co-adsorption. The adsorption energy of ethylene bonded in $\mathrm{Ti}_{5 \mathrm{C}}$ site is calculated to be $-0.56 \mathrm{eV}$ and consequently could be categorized as weak 
interaction. This is also proven by the result of the charge transfer calculation which concludes that ethylene was covalently bonded with $\mathrm{Ti}_{5 \mathrm{C}}$ site. Meanwhile the coadsorption energy calculation suggests that the $\mathrm{C}=\mathrm{C}$ bond of ethylene tends to be broken after the presence of $\mathrm{OH} \bullet$ ion. The co-adsorption energy of $-2.56 \mathrm{eV}$ is later observed that it mainly comes from the interaction between $\mathrm{OH} \bullet$ ion and its most stable Ti site.

It can also be analyzed from electronic structure calculations that there are no significant overlapping between HOMO and LUMO orbitals of ethylene, suggesting that there was no $\mathrm{C}=\mathrm{C}$ bond breaking. However, it is proven from the increasing local density of states of HOMO orbitals of ethylene that it is mainly caused by the interaction between $\mathrm{OH} \bullet$ ion and $\mathrm{Ti}_{5 \mathrm{C}}$ site.

Finally, it can be concluded that the co-adsorption interaction between $\mathrm{OH} \bullet$ ion, ethylene molecule, and $\mathrm{TiO}_{2}$ gives major contribution to the adsorption between ethylene molecule to the surface of $\mathrm{TiO}_{2}$. It weakens the bond between $\mathrm{C}=\mathrm{C}$ atoms of ethylene which could possibly contribute to the delay of the ripening process.

\section{Acknowledgement}

All computational calculations are done using facilities of Computational Material Design Laboratory, Faculty of Industrial Technology, Bandung Institute of Technology. The authors thank Program Proyek Pengembangan ITB (2013) for the financial aid of this research. Discussions between Faculty of Industrial Technology, Bandung Institute of Technology, and Department of Applied Physics, Graduate School of Engineering, Osaka University, are also acknowledged.

\section{References}

[1] L. Vermeiren, F. Devlieghere, M. van Beest, N. de Kruijf, and J. Debevere, Developments in the active packaging foods, Trends. Food Sci. Technol., 10, 1999, 77

[2] Z. B. Guzel-Seydim, A. K. Greene, and A. C. Seydim, Use of ozone in the food industry, Lebensm. -Wiss Technol., 37, 2004, 453.

[3] D. Martinez-Romero et al. Tools to Maintain Postharvest fruit and vegetable quality through the inhibition of ethylene action : A Review, Crit. Rev. Food Sci., 47, 2007, 543.

[4] G. Bailen, F. Guillen, S. Castillo, M. Serrano, D. Valero, and D. Martinez-Romero, Use of Activated Carbon inside Modified Atmosphere Packages to Maintain Tomato Fruit Quality During Cold Storage, J. Agric. Food Chem., 54, 2006, 2229.

[5] L. A. Terry, T. Ilkenhans, S. Poulston, L. Rwosell, and A. W. J. Smith, Development of New Palladium-Promoted Ethylene Scavenger, Postharvest Biol. Technol., 45, 2007, 214.

[6] K. Hashimoto et al., $\mathrm{TiO}_{2}$ Photocatalysis: A Historical Overview and Future Prospects, Jpn. J. Appl. Phys., 44, 2005, 12.

[7] C. Sun and L. Liu, Titania-water interactions: a review of theoretical studies, J. Mater. Chem., 20, 2010, 10319-10334.
[8] S.-Y. Ye et al., Photoelectrocatalytic Degradation of Ethylene by a Combination of $\mathrm{TiO}_{2}$ and Activated Carbon Felts., J. Photochem. Photobiol. A. Chem., 208, 2009, 27-35.

[9] M. E. Saltveit, Effect of Ethylene on Quality of Fresh Fruits and Vegetables, Postharvest Biol. Technol., 15, 1999, 279.

[10] M. Hussain, S. Bensaid, F. Geobaldo, G. Saracco, and N. Russo, Photocatalytic Degradation of Ethylene Emitted by Fruits with $\mathrm{TiO}_{2}$ Nanoparticles, Ind. Eng. Chem. Res., 50, 2011, 2536-2543.

[11] P. Dal-Rung, Z. Jinlong, K. Ikeue, H. Yamashita, and M. Anpo, Photocatalytic Oxidation of Ethylene to $\mathrm{CO}_{2}$ and $\mathrm{H}_{2} \mathrm{O}$ on Ultrafine Powdered $\mathrm{TiO}_{2}$ Photocatalysts in The Presence of $\mathrm{O}_{2}$ and $\mathrm{H}_{2} \mathrm{O}$, J. Catal., 185, 1999, 114-119.

[12] B. Hauchecorne, T. Tygat, S. M. Verbruggen, D. Hauchecorne, D. Terrens, M. Smits, K. Vinken, and S. Lenaerts, Photocatalytic degradation of ethylene: An FTIR in situ study under atmospheric conditions, Appl. Catal. B Environ., 105, 2011, 111.

[13] S. Yamazaki, S. Tanaka, and H. Tsukamoto, J. Photochem. Photobiol. A. Chem., 121, 1999, 55-61.

[14] H. G. Yang et al., Anatase $\mathrm{TiO}_{2}$ Single Crystals with a Large Percentage of Reactive Facets, Nature, 453, 2008, 638-642.

[15] X.-Q. Gong and A. Selloni, Reactivity of Anatase $\mathrm{TiO}_{2}$ Nanoparticles: The Role of the Minority (001) Surface, $J$. Phys. Chem. B. Lett., 109, 2005, 19560-19562.

[16] W. Gao, C.M. Wang, H.Q. Wang, V.E. Henrich, and I.E. Altman, Growth and Surface Structure of Vanadium Oxide on Anatase (001), Surf. Sci., 559, 2004, 201-213.

[17] Z. Zhao, Z. Li, and Z. Zhou, Surface properties and electronic structure of low-index stoichiometric anatase $\mathrm{TiO}_{2}$ surfaces, J. Phys. Condens. Matter, 22, 2010, 175008.

[18] A. Vittadini, A. Selloni, F.P. Rotzinger, and M. Gratzel, Structure and energetics of water adsorbed at $\mathrm{TiO}_{2}$ anatase (101) and (001) surfaces, Phys. Rev. Lett., 81(14), 1998, 2954.

[19] Selloni, Crystal growth: Anatase shows its reactive side, Nat. Mater., 7, 2008, 613.

[20] H. Ariga, T. Taniike, H. Morikawa, M. Tada, Byoung koun Min, K. Watanabe, Y. Matsumoto, S. Ikeda, K. Saiki, and Y. Iwasawa, Surface-mediated visible-light photooxidation on pure $\mathrm{TiO}_{2}$ (001), J. Am. Chem. Soc., 131, 2009, 14670.

[21] H. G. Yang, G. Liu, S. Z. Qiao, C. H. Sun, Y. G. Jin, S. C. Smith, J. Zou, H. M. Cheng, G. Q. Lu, Solvothermal Synthesis and Photoreactivity of Anatase $\mathrm{TiO}_{2}$ Nanosheets with Dominant (001), Facets. J. Am. Chem. Soc., 131, 2009, 4078.

[22] H. Zhang, Y. Wang, P. Liu, Y. Han, X. Yao, J. Zou, H. Cheng, and $\mathrm{H}$. Zhao, Anatase $\mathrm{TiO}_{2}$ Crystal Facet Growth: Mechanistic Role of Hydrofluoric Acid and Photoelectrocatalytic Activity, Appl. Mater. Interfaces, 3, 2011, 2472.

[23] W. Q. Fang, X.-Q. Gong, and H. G. Yang, On the unusual properties of anatase $\mathrm{TiO}_{2}$ exposed by high-reactive facets, $J$ Phys. Chem. Lett., 2, 2011, 725.

[24] F. Hanke, M. S. Dyer, J. Bjork, and M. Persson, Structure and stability of weakly chemisorbed ethene adsorbed on 
low-index $\mathrm{Cu}$ surfaces: performance of density functionals with van der Waals interactions, J. Phys. Condens. Matter 24.

[25] M. Lazzeri, A. Vittadini, and A. Selloni, Structure and Energetics of Stoichiometric $\mathrm{TiO}_{2}$ anatase Surfaces, Phys. Rev. B., 63, 2001, 155409.

[26] F. Labat, P. Baranek, and C. Adamo, Structural and electronic properties of selected rutile and anatase $\mathrm{tio}_{2}$ surfaces: an $a b$ initio investigation, J. Chem. Theory Comput., 4, 2008, 341-352.

[27] P. Giannozzi et al., QUANTUM ESPRESSO: a modular and open-source software project for quantum simulations of materials, J. Phys.: Condens. Matter, 21, 2009, 395502; URL http://www.quantum-espresso.org
[28] J. P. Perdew, J. A. Chevary, S. H. Vosko, K. A. Jackson, M. R. Pederson, D. J. Singh, and C. Fiolhais, Atoms, molecules, solids, and surfaces: Applications of the generalized gradient approximation for exchange and correlation, Phys. Rev. B, 46, 1992, 6671.

[29] J. P. Perdew, K. Burke, and M. Ernzerhof, Generalized gradient approximation made simple, Phys. Rev. Lett., 77, 1996, 3865.

[30] G. Shukri and H. Kasai, Density functional theory study of ethylene adsorption on clean anatase $\mathrm{TiO}_{2}(001)$ surface, Surface Science, 619, 2014, 59-66.

[31] A. Kokalj, Comp. Mater. Sci., 28, 2003, 155.

[32] Kokalj, A.D. Corso, Stefano de Gironcoli, and S. Baroni, J. Phys. Chem. B, 106, 2002, 9839. 